\title{
Does a Shark's Pectoral Fin Lowering Reflect a Human-Oriented Threat Display?
}

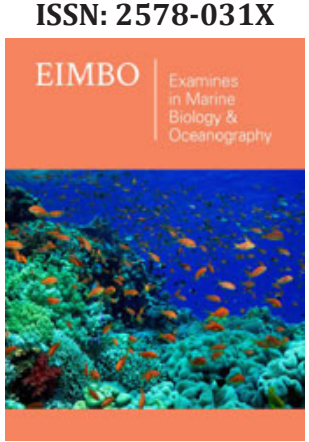

*Corresponding author: Erich K Ritter, Department of Mathematics and Statistics, Pensacola, USA

\section{Submission: 㘹 September 03, 2019}

Published: 想September 19, 2019

Volume 3 - Issue 1

How to cite this article: Erich K Ritter. Does a Shark's Pectoral Fin Lowering Reflect a Human-Oriented Threat Display? Examines Mar Biol Oceanogr. 3(1). EIMB0.000555.2019.

DOI: 10.31031/EIMBO.2019.03.000555

Copyright@ Erich K Ritter, This article is distributed under the terms of the Creative Commons Attribution 4.0 International License, which permits unrestricted use and redistribution provided that the original author and source are credited.

\author{
Erich K Ritter ${ }^{1,2 *}$ \\ ${ }^{1}$ Department of Mathematics and Statistics, USA \\ ${ }^{2}$ Shark Research Institute, Princeton, USA
}

\begin{abstract}
Pectoral fin lowering among sharks has habitually been interpreted as a threat display towards humans. A different form of such lowering, called 'pectoral burst,' a quick drop of both pectoral fins into a vertical position for steering and accelerating purposes, is used to question this old threat display assumption, and a new interpretation is given about what lowered pectorals likely reflect.
\end{abstract}

Keywords: Agonistic display; Human; Hunching; Pectoral fin; Shark; Threat

\section{Introduction}

Most of the time, sharks swim rather slowly with their pectoral fins used as their primary form of steering [1-3]. If a change of direction is needed, one of the two pectorals is turned slightly down to increase resistance while simultaneously being slightly rotated forward, leading the shark to the new bearing. If a quicker adjustment of direction is needed, said pectoral fin is turned down and rotated faster with its main axis moved more vertically. Here, a bull shark, Carcharhinus leucas, is shown performing such a quick turn, where both pectoral fins were drop into a vertical position along with a simultaneous twist of one of the two fins to enhance steering. This performance is further called a 'pectoral burst' due to the acceleration created. This mechanism is supported by lateral body muscles, and tail twist, commonly called a C-start [4-6]. However, as will be shown here, the pectoral burst is the crucial element in executing the shark's turn, connected to immediate forward propulsion and a subsequent gliding phase.

Two aspects are discussed, the essential physical elements of the pectoral burst, and the validity of lowering pectoral fins as part of a generally accepted threat display among sharks directed towards humans [7-9], as first described by Johnson and Nelson in 1973 [10]. Clear evidence towards a threatening manner was never offered, and a more feasible interpretation is suggested of what lowered and lowering pectoral fins likely represent.

\section{Method and Result}

On March 15, 2019, a mature female bull shark was observed in the greater area of "Tiger Beach," a large site on the outer banks of the northwestern Bahamas. The site's depth was about $15 \mathrm{~m}$, with a mixed sandy bottom and low reef formation. The video was taken with a GoPro 7 in $2.7 \mathrm{~K}$ density, and $60 \mathrm{fps}$, frame by frame explanations are given in 1/100 seconds increments. The bull shark in question swam no more than $1 \mathrm{~m}$ off the ground in the general direction of the stationary videographer. There was no physical barrier other than the actual bottom and the close vicinity of the shark to the person. Other sharks present at the site, albeit not close to interfere with the bull shark, were a few Caribbean reef sharks, C. perezi, lemon sharks, Negaprion brevirostris, and three tiger sharks, Galeocerdo cuvier. The following description is divided into three segments, "approach," "turn", and "glide."

\section{Approach}

A shark's inner circle is the minimal area surrounding its body, needed to maneuver freely [11]. For most sharks, the radius of their inner circle is about two body lengths [1214], while for bull sharks it is around 1.4 body lengths [12]. The bull shark swam in a roughly head-on direction towards the stationary videographer and reached a point where it needed 
to adapt its pattern to avoid passing the videographer within its inner circle [12-14]. The shark started to turn to its left towards an unobstructed area. Despite this turn, its path brought it as close as about one body length to the videographer. This distance must not have been sufficient for the shark's comfort, which likely triggered the additional turn and acceleration.

\section{Turn}

The shark was gliding towards the videographer with some momentum that started to bring it close to the videographer, thus veering off to the left needed to be done rather quickly to avoid getting any closer. The following turn sequence starts at 0 seconds (Figure 1a). Although the shark was continuously moving forward, its body followed the general unilateral muscle contraction commonly described as a C-start [4-6,15] (see additional explanations further below). This contraction is succeeded by a supporting flip of the tail, which accelerated the animal in the new line of movement away from the videographer. The entire display started with a drop of the pectoral fins, during which the fins reached their vertical position in 0.08 seconds and where the left fin was also pivoted to enhance the turn (Figure 1b/12). The involvement of the pelvic fins was also noticeable. Although the right one could have been passively dropped due to the turn, the left one was actively lowered since the left turn would have remained in a flat position. After 0.16 seconds, the shark started to glide into the new direction with the left pectoral fin still pivoted to keep maintaining the left turn (Figure 1c/16). The left pectoral fin then was pivoted further while the turn progressed (Figure 1d/20). Both pectoral and pelvic fins remained in the dropped position (Figure 1e/52), until the shark began a glide in the final direction (Figure 1f/80).

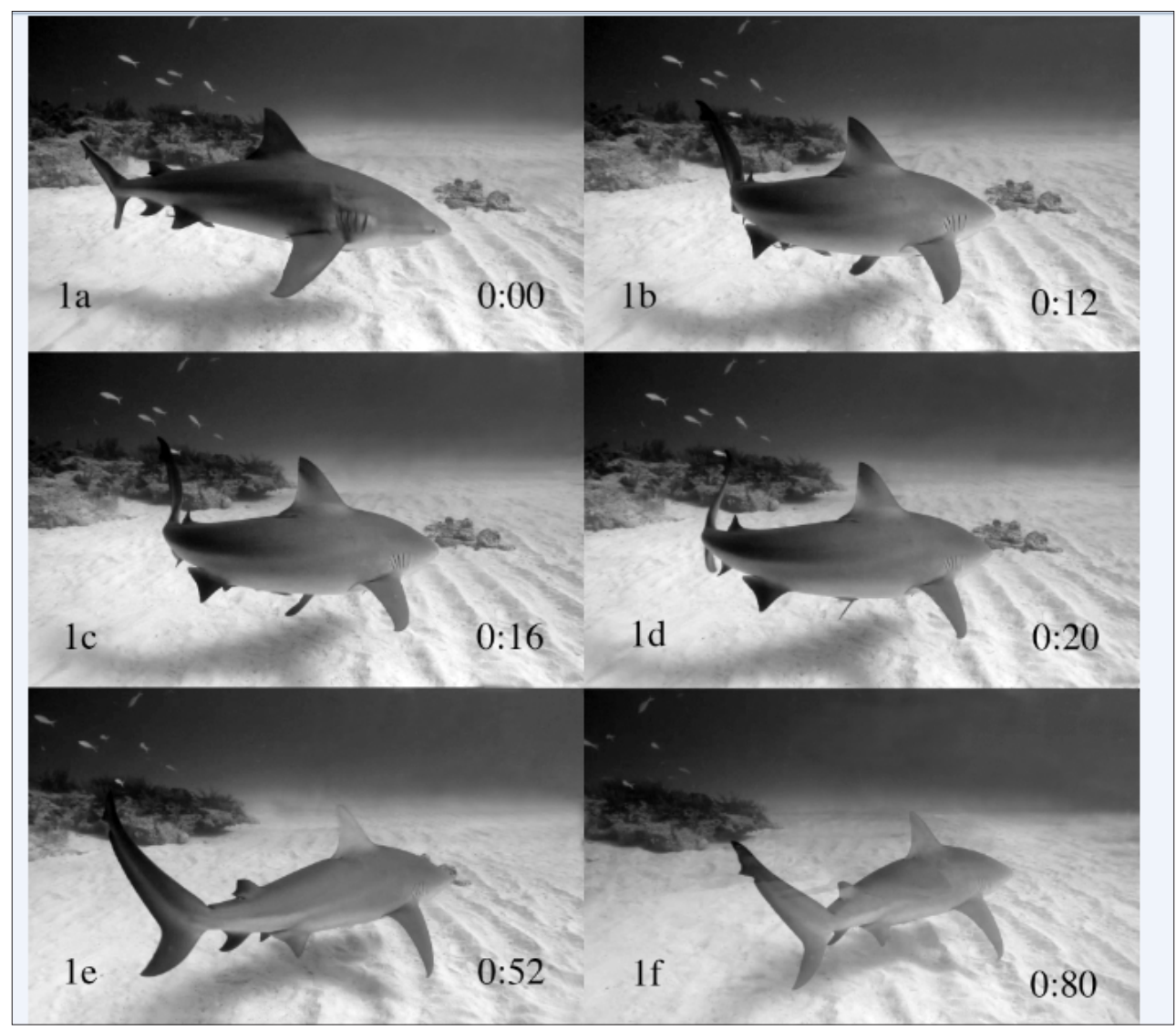

Figure 1: Pectoral burst of a bull shark.

1a) Initial position.

1b-e) Different phases of the pectoral burst's turn.

1e) Initial gliding position.

1f) Continuous gliding position. Number in the lower right corner: Time in 1/100 seconds.

\section{Glide}

Acceleration was gathered throughout the pectoral burst. The shark maintained the dropped pectoral fins while starting to glide (Figure 1f/80), which allowed the shark to still maneuver quickly should another diver or structure appear in its path. The glide maintained its initial direction until the shark resumed its regular tailbeat frequency.

\section{Discussion}

When the shark needs to accelerate from a near standstill, the entire body is bent to one side through a unilateral muscle contraction commonly labeled a C-or S-start $[6,15,16]$. When it comes to sharks with their large pectoral fins, this type of body bending is supported by quickly lowering both pectoral fins. Unfortunately, should pectoral fin lowering occur when the shark 
is close to a person, its meaning is habitually interpreted as a threat display, but this interpretation has never been questioned. Thus, here, the validity of interpreting lowering pectoral fins as a putative threat display against humans is discussed, as well as the mechanics of the quick lowering of pectoral fins.

\section{Maneuvering ability of a shark}

Pectoral fins represent the main steering extremities of sharks [1-3]. By lowering one of the two fins, along with a slight forward rotation along the fin's main axis, a drag is produced; thus, a turn is initiated to the side on which the pectoral fin is lowered. When acceleration and steering are crucial, both pectoral fins are lowered quickly to increase maneuverability. Depending on the situation, after the initial pectoral burst, the shark either actively swims away or starts to glide, as seen in this example. In this case, the shark kept its pectoral fins lowered during the gliding phase. This position maintains the increased lateral surface of the fins, making any slight direction change very responsive and quick.

\section{Forward acceleration}

Lowering pectoral fins quickly causes an increase in water friction and displacement. Due to the angle and lowered position of the pectoral fins, they displace water towards each other and backward, resulting in a forward motion. Along with the support of the body bending and tail flip, they seem to create the acceleration that was seen here. In contrast, when sharks lower both their pectorals slowly, no acceleration is noticed (pers. obs.), thus the more quickly the pectorals are lowered, the faster a shark is propelled forward. There is also a large amount of literature available that deals with the interaction between escape speed and reaction distance [17-19]. The close approach of one body length between the bull shark and the videographer indicates that the shark had a relatively high tolerance level towards this unfamiliar object, but the reaction afterward follows a somewhat stereotyped performance.

To what extent sensory organs other than the eyes play a role here, cannot be said. Although the lateral line system was clearly in the range of picking up any water pressure that would have originated from the videographer [20-22], his stationary position likely did not create any.

\section{Agonistic display}

Pectoral fin lowering in sharks has commonly been accepted as a threat display towards humans [7-9], although the original work of Johnson and Nelson in 1973 [10] did not offer definite proof. Johnson and Nelsen observed grey reef sharks, Carcharhinus menissorah (=amlyrhynchus), performing posturing that eventually led to their paper on agonistic display [10]. They described this posturing as follows:

An agonistic display directed toward divers was observed... consist of two locomotor elements... and four postural elements:

A. Lifting of the snout.

B.Dropping of the pectoral fins.

\section{C.Arching of the back and}

D. Lateral bending of the body.

" Over the years, this putative threat display was mostly reduced to the two main features: lowered pectoral fins $[8,9,23]$, and hunching, the arching of the shark's back, connected to an awkward swimming posture. The paper continues “...laterally exaggerated swimming motion and lateral body tilting (rolling), and/or spiral looping (spiral up and down movement through the water, more pronounced in the anterior region) ..." [10]. This very display of 'exaggerated swimming motion and lateral body tilting' is identical to shark sucker-induced behavior patterns [24], and it is no surprise that in the original photos of Johnson and Nelson [10], sharksuckers were attached to the performing sharks. Still, the authors' initial interpretation of being a threat display was never questioned, primarily because the posturing was performed in the vicinity of humans. So whenever lowered pectorals were seen or mentioned, the conclusion was continually made that it reflected a human-oriented threat display $[8,9,23]$.

\section{Questioning agonistic display of sharks towards humans}

Agonistic display has been defined in a variety of forms, and a comprehensive checklist has been given by Számadó [25]. It says threat display:

\section{A. Should be significantly associated with attacks.}

B.Should be always addressed at close range.

C. Should be always addressed to one well-defined receiver.

D. No-response should not be accepted as a reply and

E.Different displays should be associated with different replies.

The fallacy of interpreting lowered pectoral fins as a threat display is reflected in the failure of four of the five elements that define a threat display mentioned above.

A. Shark incidents are very rare despite the huge number of people entering the water at any given time; thus, a threat display should be significantly associated with attacks, but it is not.

B.The display should be directed to a specific recipient, after which a predictable reaction can be expected. However, if the shark display is toward an unfamiliar object such as a human, no specific reaction can be guaranteed.

C.Further, a no-response by the recipient of the threat signal should not be accepted. Although lowered pectoral fins have supposedly been noticed in a variety of species [10], there has only been one reported incident where the shark displayed its discomfort before an incident [26]. In all other cases where the supposed threat display was observed, no attack followed the noresponse of the observer [27].

D. Lastly, the potential receiver of the threat must be able to pinpoint the display with high accuracy. Such is hardly the case, considering that humans, as just mentioned, are unknown entities to sharks. 
While lowering pectorals may fit the second listed criterion for a threat display mentioned by Számadó [25], as it must always occur rather close to a person based on Johnson and Nelson [10], this is likely just an artifact of the presence of an observer. Recalling the inner circle, the 3-dimensional space a shark needs to be able to turn freely [11-14]. Besides, a shark loses the capacity for binocular vision when it gets closer to its inner circle should it not approach in a frontal manner. Therefore, it may be that the threshold of the inner circle of a shark reflects the flight initiation distance [28-30] where a shark needs to use its most effective response to get away as quickly as possible. In some cases, this could be a C-start, or it could be a C-start that is combined with quickly lowering pectoral fins. It has also been observed (pers. obs.) that sharks can slowly lower their pectorals before they reach this threshold with humans in front of them as if they try to make themselves ready for a quick escape. So, if a shark stays outside the inner circle [11], there are not likely to be human-induced triggers causing the shark to lower its pectoral fins for a quick turn. That also goes for the oftenmentioned cornering of a shark [10]. Due to the inner circle, sharks are very aware of such restrictions and withdraw most often before space gets too tight.

\section{Could pectoral fin lowering represent a shark feeling threatened?}

Johnson and Nelson [10] mentioned that lowering pectoral fins expresses a threat display in human presence. What they did not take into account was that lowering pectoral fins could have reflected the opposite situation, namely that the shark is feeling threatened, or at least vigilant, and by lowering its pectorals, the shark expresses such discomfort and makes itself ready to escape if necessary but not announce the opposite of a potential incident.

The interpretation of the presented scenario, in which the bull shark approached the videographer without any restrictive topography limiting the escape routes to the sides, is that the shark got too close to the videographer and felt the need to react, likely indicating that it felt threatened by the videographer's stationary presence.

\section{Conclusion}

Based on the commonly accepted recommendation of what a threat display should entail and how the target should react, a shark's putative threat display of lowered pectoral fins, aimed at humans, must be rejected.

\section{References}

1. Fish FE, Shannahan LD (2000) The role of the pectoral fins in body trim of sharks. J Fish Biol 56(5): 1062-1073.

2. Wilga CD, Lauder GV (2000) Three-dimensional kinematics and wake structure of the pectoral fins during locomotion in leopard sharks Triakis semifasciata. J Exp Biol 203(15): 2261-2278.

3. Maia AMR, Wilga CAD, Lauder GV (2012) Biomechanics of locomotion in sharks, rays, and chimaeras. In: Carrier JC, Musick JA, Heithaus MR (Eds.), Biology of sharks and their relatives. CRC Press, Boca Raton, USA.

4. Foreman MB, Eaton RC (1993) The direction change concept for reticulospinal control of goldfish escape. J Neurosci 13(10): 4101-4133.
5. Jayne BC, Lauder, GV (1993) Red and white muscle activity and kinematics of the escape response of bluegill sunfish during swimming. J Comp Physiol A 173(4): 495-508.

6. Domenici P, Blake RW (1997) The kinematics and performance of faststart swimming. J Exp Biol 200(8): 1165-1178.

7. Martin RA (2007) A review of shark agonistic displays: Comparison of display features and implications for shark-human interactions. Mar Freshw Behav Physiol 40(1): 3-34.

8. Smith K, Scarr M, Scarpaci C (2010) Grey nurse shark (Carcharias taurus) diving tourism: Tourist compliance and shark behaviour at Fish Rock, Australia. Environ Manage 46(5): 699-710.

9. Clarke CR, Lea JSE, Ormond RFG (2013) Changing relative abundance and behaviour of silky and grey reef sharks baited over 12years on a Red Sea reef. Mar Freshw Res 64(10): 909-919.

10. Johnson RH, Nelson DR (1973) Agonistic display in the gray reef shark, Carcharhinus menisorrah, and its relationship to attacks on man. Copeia 1973(1): 76-84.

11. Ritter EK (2018) Shark-human interaction ( $2^{\text {nd }}$ edn), Situations Findings Recommendations. Shark School Publishing, Pensacola, USA p. 205.

12. Ritter EK, Amin RW (2012) Effect of human body position on the swimming behavior of bull sharks, Carcharhinus leucas. Soc Anim 20(3): 225-235.

13. Ritter EK, Amin R (2014) Are Caribbean reef sharks, Carcharhinus perezi, able to perceive human body orientation? Anim Cogn 17(3): 745-753.

14. Ritter EK, Amin R (2015) A study of shark stealth behavior in the proximity of divers. Open J Anim Sci 5(2): 224-228.

15. Domenici P, Blake R (1993) Escape trajectories in angelfish (Pterophyllum eimekei). J Exp Biol 177: 253-272.

16. Wakeling JM (2005) Fast-start mechanics. Fish Physiol 23: 333-368.

17. Helfman GS, Winkelman DL (1997) Threat sensitivity in bicolor damselfish: Effects of sociality and body size. Ethology 103(5): 369-383.

18. Semeniuk CAD, Dill LM (2004) Cost/benefit analysis of group and solitary resting in the cowtail stingray, Pastinachus sephen. Behav Ecol 16(2): 417-426.

19. Domenici P (2010) Context-dependent variability in the components of fish escape response: Integrating locomotor performance and behavior. J Exp Zool Part A: Ecol Gen Physiol 313(2): 59-79.

20. Mirjany M, Preuss T, Faber SD (2011) Role of the lateral line mechanosensory system in directionality of goldfish auditory evoked escape response. J Exp Biol 214(20): 3358-3367.

21. Higgs DM, Radford CA (2013) The contribution of the lateral line to hearing in fish. J Exp Biol 216(8): 1484-1490.

22. Seamone S, Blaine T, Higham TE (2014) Sharks modulate their escape behavior in response to predator size, speed and approach orientation. Zoology 117(6): 377-382.

23. Smith KR, Scarpaci C, Louden BM, Otway MN (2015) Behaviour of aggregated grey nurse sharks Carcharias taurus off eastern Australia: Similarities and differences among life-history stages and sites. Endangered Species Res 27(1): 69-85.

24. Ritter EK (2002) Analysis of sharksucker, Echeneis naucrates, induced behavior patterns in the blacktip shark, Carcharhinus limbatus. Environ Biol Fish 65(1): 111-115.

25. Szamado S (2003) Threat displays are not handicaps. J Theor Biol 221(3): 327-348.

26. Nelson DR, Johnson RR, McKibben JN, Pittenger GG (1986) Agonistic attacks on divers and submersibles by gray reef sharks, Carcharhinus amblyrhynchos: Antipredatory or competitive? Bull Mar Sci 38(1): 6888. 
27. GSAF (2019) Global shark attack file/shark research institute, incident $\log$, USA.

28. Frid A, Dill L (2002) Human-caused disturbance stimuli as a form of predation risk. Conserv Ecol 6(1): 11.
29. Stankowich T, Blumstein DT (2005) Fear in animals: A meta-analysis and review of risk management. Proc R Soc 272(15810): 2627-2634.

30. Cooper WE, Frederick WG (2007) Optimal fight initiation distance. J Theor Biol 244(1): 59-67.

For possible submissions Click below: 